\title{
Enhancement of Human Anatomy and Nervous System Learning using Mobile Augmented Reality Application
}

\author{
Rubaiya Hafiz, Jahidul Hasan, Md. Azizul Hakim
}

\begin{abstract}
Advancements of recent technology allows the delivery of educational materials to be highly interactive. Augmented reality (AR) is one of the most promising technology that augments reality with computer generated imagery, objects, information etc. and allows user interaction. By providing visualization and interactive $3 D$ models, it allows students to understand any abstract concept on any time, at any place easily. In this work we have developed an AR based mobile application that can create an interactive $3 D$ view of human skeleton and nervous system by using a target image captured by a mobile phone camera. The main motive of this application is to help the medical students and school level science students to learn human anatomy and nervous system in an interactive way so that they can enhance their learning procedure. This research narrates the concept, application development and results of the pilot test. This test is conducted by the medical students of different medical colleges of Bangladesh. We have done this pilot test to get the users' experiences from technical viewpoint. According to this test we can concluded that students were satisfied with this application in terms of the features, usability, feasibility and understandability.
\end{abstract}

Keywords: Augmented Reality, Anatomy Learning, Mobile Augmented Reality, Nervous System.

\section{INTRODUCTION}

\section{A} ugmented Reality (AR) is an emerging technology that enhance the reality with computer generated two or three dimensional images. It employs different information from real world to provide an integrated view of a particular real world object and offers interaction with it. A mobile based augmented reality application (mAR) provides mobilized, flexible and user interactive learning environment to users which is independent of time and

Revised Manuscript Received on February 17, 2020.

* Correspondence Author

Rubaiya Hafiz*, Computer Science and Engineering, Daffodil International University, Dhaka, Bangladesh. Email: rubaiya.cse@diu.edu.bd

Jahidul Hasan, Computer Science and Engineering, Daffodil International University, Dhaka, Bangladesh. Email: jahidul156961@diu.edu.bd International University, Dhaka, Bangladesh. Email: azizul.cse@diu.edu.bd

(C) The Authors. Published by Blue Eyes Intelligence Engineering and Sciences Publication (BEIESP). This is an open access article under the CC BY-NC-ND license (http://creativecommons.org/licenses/by-nc-nd/4.0/)
Md. Azizul Hakim, Computer Science and Engineering, Daffodil

location. Anatomy and nervous systems are some of the most important subjects especially for medical students and school level science students. Human anatomy and nervous system learning is concerned with the recognition and narration of human body structures which needs proper visualization of imagination to know the names and operations of different body organs and their activities. That's why these learning involves practical vivisection in the laboratory, where internal structure of human body and animals get revealed. This practical session is needed so that students can learn complex things more accurately. But after completing this session it becomes difficult for students to memorize the topics because it could not grow deep rooted understanding of this subject [1]. However, mobile based augmented reality application can be one possible solution of this problem which can makes a concept fully understandable to students by illustrating a responsive 360degree view of a model in the actual environment, actual scale, and any time and at any place.

Using target images collected from books or a downloaded document from websites or from printouts, a mobile based augmented reality application can scan images through the camera of a smartphone and can generate a $3 \mathrm{D}$ view of images that can help both the teachers and the students by giving them immersive environment. This application can also be considered as an economical option for introducing a modern aspect to 2D images and physical objects.

This paper aims to discuss the development and testing of an augmented reality (AR) application for teaching as well as learning anatomy, nervous system, different bones, eye etc. for human body. Section II discusses the literature review; Section III describes the application architecture of the proposed AR application; Section IV discuss about pilot testing and students feedback after using this application. This paper concludes at Section VI

\section{LITERATURE REVIEW}

\section{A. Existing AR Based System}

According to a report, 68.7 million (20.8\% of the overall population) people in USA use AR at least once per month in 2019 [2]. Some of the applications of AR include gaming [3], entertainment, archaeology [4], architecture [5], commerce [6], tourism [7] etc.

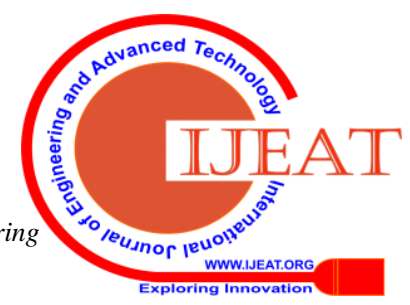




\section{Enhancement of Human Anatomy and Nervous System Learning using Mobile Augmented Reality}

Application

Several published work focused on utilization of augmented reality in education and most of them get positive results [8]. Study conducted by Kaya and Bicen [9] reveals that the applications augmented reality in educational environments has a positive impact and it increases the academic achievement of students. Joanne Yip et al. [10] have conducted a study on a sewing workshop and found that the use of AR videos provides better learning result in terms of learning performance and efficiency compared with the use of hand- outs in classes. The participants included 46 freshmen and this study showed that students' learning experience and understanding of complex concepts can be enhanced through AR videos.

Studies found that generally students perceived successful learning of anatomy through various combinations of memorization, under- standing as well as visualization [11].

\section{B. AR Based Medical Training System}

AR can be used in other medical training also. T Blum et al. [12] have proposed an ultrasound (US) simulator based on AR in which contextual in-situ techniques are imposed to visualize the location of US slice inside the body. J Barrow et al. have introduced an augmented reality (AR) application to educate medical students about metabolism, especially glucose metabolism and insulin signaling [8].

\section{Existing AR based Mobile/Web Application for anatomy learning}

Umeda et al. [13] have proposed an AR based medical training system to show some three dimensional anatomical objects like skeleton, heart and organs. Human Anatomy in Mobile Augmented Reality or HuMAR, a process developed by $\mathrm{S} S$ Jamali et al. to enhance students overall learning process. The prototype model can be able to give students both description and location of different human bones as well as their reference links [14]. To teach anatomy T Blum et al. have presented a magic mirror based on AR so that the user can understand the spatial relations between his body and the virtual interaction plane [15]. An AR based medical anatomy edutainment system was proposed by P Stefan et al. that supports gesture based interaction with user [16].

Anatomy, nervous system, and all other organs learning are some of the beginner and basic subjects in medical colleges in Bangladesh. It is quite a big challenge for any new comer Bengali-based learner to memorize these terminologies as well as their functionality since all the textbooks were written by English speaking background (ESB) writers [17]. This is why we proposed a mobile-AR based application to assist and improve students selflearning skills. Our application can model human Skeletal, Bones, Nervous System, Brain and Eye by using extended features such as separate viewing angle, rotation option, zoom in/out option etc. A comparison of our application with other applications is shown in Table I.

\section{APPLICATION ARCHITECTURE}

The overall architecture of our proposed model is shown in Fig. 1 and it consists of the following three major phases.

\section{A. Technical Requirement}

Technical requirements are the set of hard- ware issues that must be considered to operate a product effectively. We have selected mobile phones (both IOS and Android) to project AR objects and the minimum API requirement for the smooth running of this application is version 4.1(Jelly Bean) and version 7.0.1 for IOS. The target images are captured using back camera and the resultant augmentations are exhibited through front panel display screen.

\section{B. 3D Model Building}

Autodesk Maya, version 2016 is used for modeling each of the 3D objects. All the features were transformed into this software to develop models. With the guideline of anatomical expert, each part was deconstructed within Autodesk Maya into several components and then accurately positioned according to the skeletal and nervous system. As a result this system provides more detail user understandings. Textures were mapped to make each component more realistic in 3D form. Table II shows all developed model and their features.

\section{Software Development Kit}

An AR extension is required for producing an augmented environment. Vuforia is a soft- ware platform that is designed for high quantity operation of AR on mobile devices. It also provides tools for creating all categories of AR experience. A mobile educational courseware application approach was employed in our pro- posed system. Vuforia extension was integrated into Autodesk Maya as well as Unity3D (version 2019, 30a2 (Alpha)) for rendering and tracking AR. All 3D components (in .fbx file format) were exported to Unity3D software and incorporated with Vuforia. Unity3D gives all necessary tools for labeling and describing objects to provide relevant information to students.

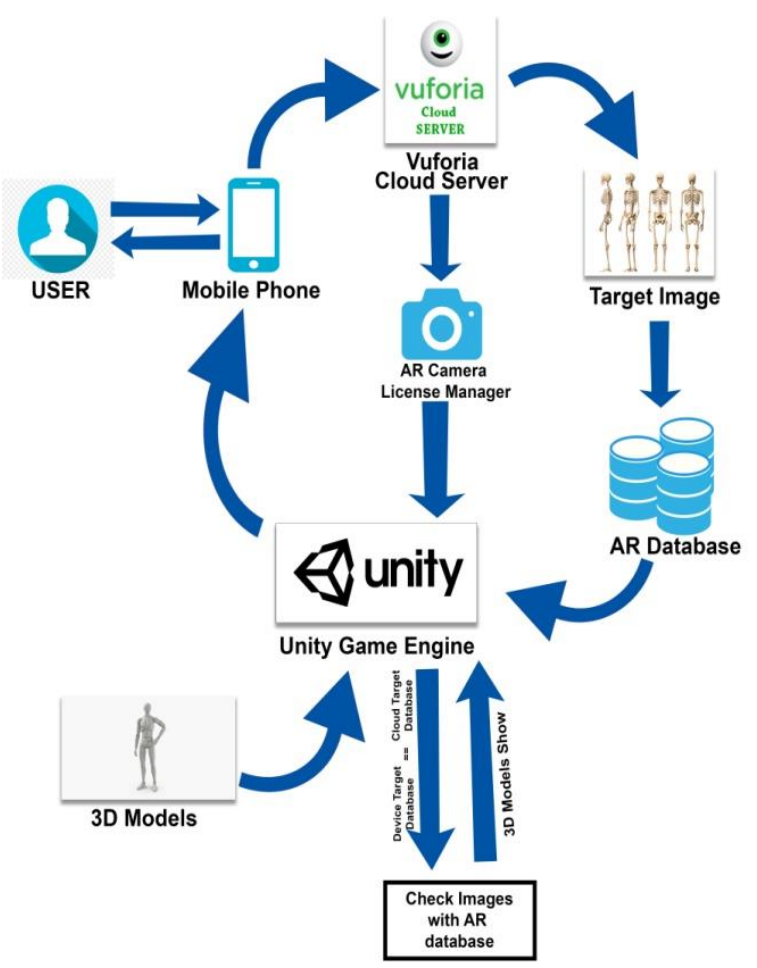

Fig. 1.Application Architechture of Proposed Approach
Published By:

Blue Eyes Intelligence Engineering \& Sciences Publication 


\section{RESULTS AND DISCUSSIONS}

A. Pilot Testing Result and Application Usage Feedback
Some sample screenshots showing this application running on an Android mobile are shown

Table- I: Summary of Existing System and Comparison with Our System

\begin{tabular}{|c|c|c|c|c|c|c|c|}
\hline \multirow{2}{*}{$\begin{array}{l}\text { Name of } \\
\text { System }\end{array}$} & \multirow[t]{2}{*}{ AR models } & \multirow[t]{2}{*}{ Features } & \multicolumn{3}{|c|}{ Type of App } & \multirow[t]{2}{*}{ Primary User } & \multirow{2}{*}{$\begin{array}{l}\text { Pilot } \\
\text { testing }\end{array}$} \\
\hline & & & 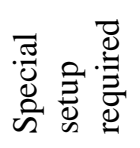 & 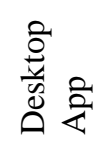 & 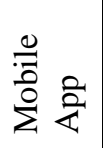 & & \\
\hline [13] & $\begin{array}{l}\text { Heart } \\
\text { Skeleton } \\
\text { Organs }\end{array}$ & 3D view of each part & Yes & & & $\begin{array}{l}\text { Medical school } \\
\text { students }\end{array}$ & No \\
\hline $\begin{array}{c}\text { HuMAR } \\
{[14]}\end{array}$ & Anatomy & $\begin{array}{l}\text { Human skeletal } \\
\text { structure }\end{array}$ & & & Yes & $\begin{array}{l}\text { Medical school } \\
\text { students }\end{array}$ & Yes \\
\hline $\begin{array}{c}\text { Mirracle } \\
\text { [15] }\end{array}$ & Organs & $\begin{array}{l}\text { Gesture based } \\
\text { Interaction } \\
\text { Text information }\end{array}$ & Yes & & & $\begin{array}{c}\text { Education of } \\
\text { anatomy in } \\
\text { classrooms, museums } \\
\text { or exhibitions. }\end{array}$ & No \\
\hline $\begin{array}{c}\text { AR bone } \\
\text { puzzle [16] }\end{array}$ & Human bone & $\begin{array}{l}\text { Users learn by } \\
\text { assembling the virtual } \\
\text { bone pieces on their } \\
\text { body. } \\
\text { Gesture based } \\
\text { interaction. }\end{array}$ & Yes & & & $\begin{array}{l}\text { Medical students and } \\
\text { young children }\end{array}$ & Yes \\
\hline $\begin{array}{c}\text { Our } \\
\text { proposed } \\
\text { system }\end{array}$ & $\begin{array}{l}\text { Anatomy } \\
\text { Organs } \\
\text { (Brain, Eye } \\
\text { etc.) }\end{array}$ & $\begin{array}{l}\text { 3D anatomical view } \\
\text { with text based } \\
\text { information of } \\
\text { different parts } \\
\text { User can select each } \\
\text { any part for further } \\
\text { inspection } \\
\text { Supports zoomed } \\
\text { in/out, image } \\
\text { capturing etc. }\end{array}$ & & & Yes & $\begin{array}{l}\text { Medical as well as } \\
\text { other students. }\end{array}$ & Yes \\
\hline
\end{tabular}

Table- II: Model Description with Available Features

\begin{tabular}{|l|l|l|}
\hline \multicolumn{1}{|c|}{ Models } & \multicolumn{1}{|c|}{ Description } & \multicolumn{1}{c|}{ Feature } \\
\hline Skeletal & Labeled view of human skeleton. & $\begin{array}{l}\text { Individual parts of skeleton and nervous system can be } \\
\text { selected separately to make them clear. }\end{array}$ \\
\cline { 1 - 2 } Bone & $\begin{array}{l}\text { Bone description, Labels of each } \\
\text { part. }\end{array}$ & $\begin{array}{l}\text { Rotation, Zoom in/out of each model for close and detailed } \\
\text { inspection. }\end{array}$ \\
\cline { 1 - 2 } $\begin{array}{l}\text { Nervous } \\
\text { system }\end{array}$ & $\begin{array}{l}\text { Labeled view of human nervous } \\
\text { system. }\end{array}$ & $\begin{array}{l}\text { User can be able to capture pictures of what they are } \\
\text { viewing in the display screen. }\end{array}$ \\
\hline Brain & Labeled view of human brain. \\
\cline { 1 - 2 } Eye & Labeled view of human eye. & \multicolumn{2}{|l}{}
\end{tabular}




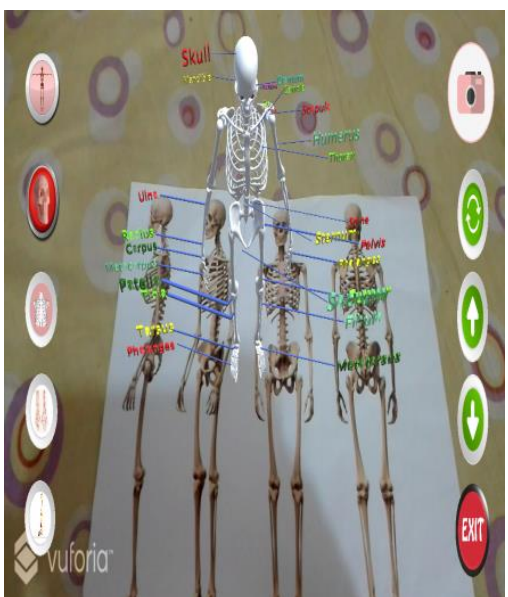

(a)

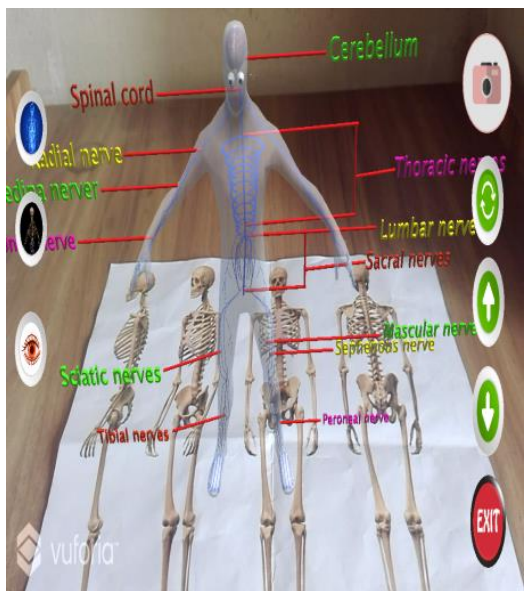

(d)

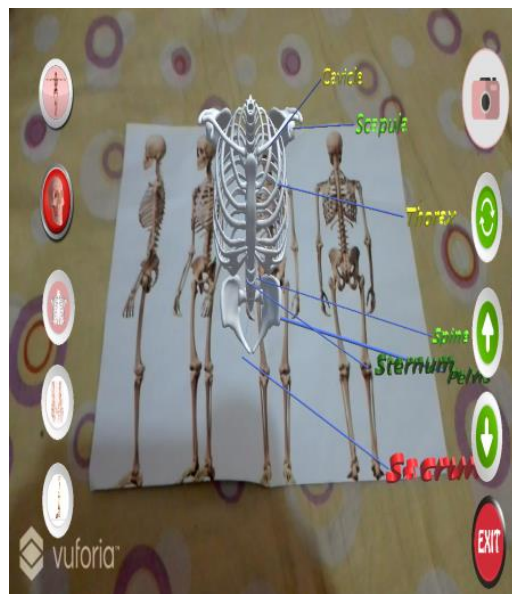

(b)

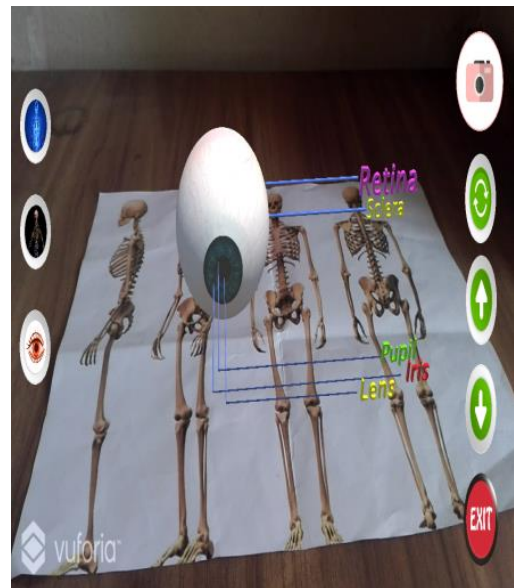

(e)

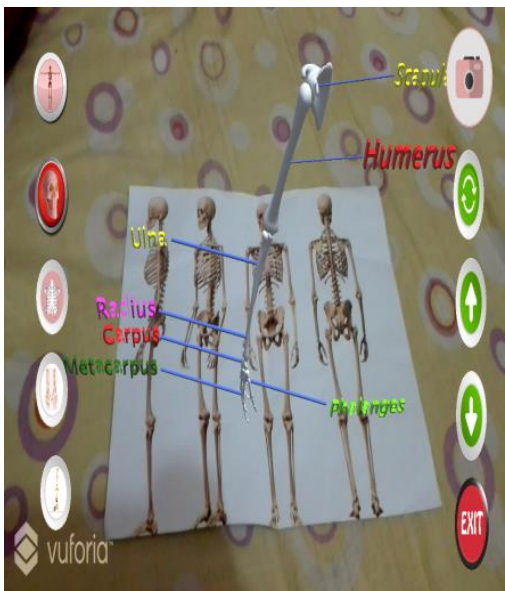

(c)

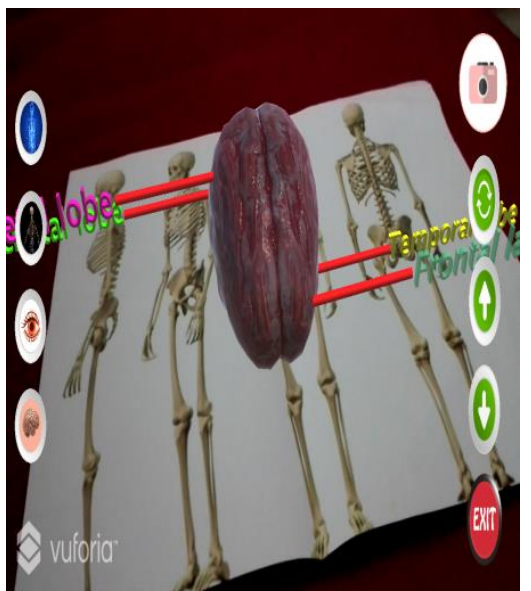

(f)

Fig. 2. Sample AR objects from our proposed application running on an Android mobile. (a)Labeled human skeleton,

(b) Separately selected chest area, (c) Labeled arm area, (d) Labeled nervous system, (e) selected eye area, (f)human brain

Table- III: Model Description with Available Features

\begin{tabular}{|c|c|c|c|c|c|c|}
\hline & Question 1 & Question 2 & Question 3 & Question 3 & Question 5 & Question 6 \\
\hline Strongly Agree & $95.23 \%$ & $80.96 \%$ & $96.83 \%$ & $92.07 \%$ & $90.48 \%$ & $76.19 \%$ \\
\hline Agree & $4.76 \%$ & $15.87 \%$ & $3.17 \%$ & $7.93 \%$ & $9.52 \%$ & $15.88 \%$ \\
\hline Neutral & 0 & $3.17 \%$ & 0 & 0 & 0 & $4.76 \%$ \\
\hline Disagree & 0 & 0 & 0 & 0 & 0 & $3.17 \%$ \\
\hline Strongly Disagree & 0 & 0 & 0 & 0 & 0 & 0 \\
\hline
\end{tabular}

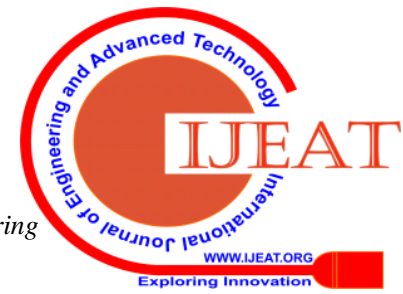


120

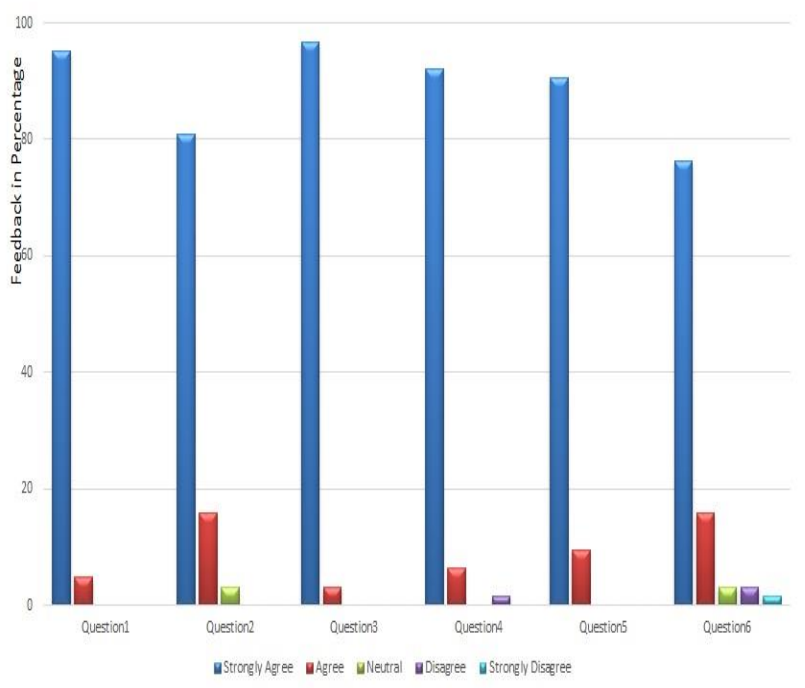

Fig. 3. Students Feedback

in Fig. 2. To calculate the reliability and performance of the proposed system, at first we have conducted pilot testing. Then a questionnaire (attached in appendix) is served among 63 randomly chosen students to collect feedback. Our intention was to find if they are interested in AR based learning environment or not. $50 \%$ of them strongly agreed, $40 \%$ agreed and $10 \%$ gave neutral feedback that through visualization AR based system provides better understanding. 35\% strongly agreed and 50\% agreed that this system is useful to enhance their learning. 35\% participants strongly agreed, 25\% agreed, 5\% neutral, 20\% disagreed and $15 \%$ strongly disagreed that this application will be more effective if it contains more models as well as features.

Moreover, students stated "We didn't have any kind of AR (Augmented Reality) based class before"; "this system is more useful for junior rather than senior students". All of their feedbacks are plotted into a chart as shown in Fig. 3 and the statistics of their feedbacks are shown in Table III.

\section{CONCLUSION}

Our application provides an interactive way for both medical and school level science students and instructors to learn and teach complex concepts of human anatomy and nervous system. This work, we have analyzed different AR based application in different sectors of education. We have received positive feedback from the end-users as well. Our application works both in Android and IOS operating system, so this application is operating system independent. In future we will stress on the robustness of this application. We will try to add virtual reality in order to enhance this type of visualization.

\section{ACKNOWLEGEMENT}

Authors' would like to thank the Department of Computer Science and Engineering of Daffodil International University, Dhaka, Bangladesh for their spontaneous support and encouragement for completing this research work.

\section{REFERENCES}

1. P. K. Ganguly,. "Teaching and Learning of Anatomy in the 21st Century: Direction and the Strategies." The Open Medical Education Journal 3.1 (2010).

2. V. Petrock, "Virtual and Augmented Reality Users2019," March 2019 (Accessed September 30, 2019). https:/www.emarketer.com/content/virtual-and-augmented-realityusers-2019/.

3. M. Russ, et al. "Augmented reality systems and methods for gaming." U.S. Patent Application No. 15/672,560.

4. A. Berlino, et al. "Augmented reality for the enhancement of archaeological heritage: a calabrian experience," 2019.

5. R. A. Zemenchik, "System For Treatment Of An Agricultural Field Using An Augmented Reality Visualization," May 16 2019. U.S. Patent Application No. 16/148,142.

6. N. Spivack and M. Hoerl, "Systems and methods ofrewards object spawning and augmented reality commerce platform supporting multiple seller entities," Apr. 11 2019. US Patent App. 16/130,582.

7. D.-I. D. Han, M. C. T. Dieck, and T. Jung, "Augmented Reality Smart Glasses (ARSG) visitor adoption in cultural tourism," Leisure Studies 38.5 (2019): 618-633.

8. J. Barrow, et al. "Augmented reality for enhancing life science education," Proc. of VISUAL. 2019.

9. O. S. Kaya and H. Bicen, "Study of Augmented Reality Applications Use in Education and Its Effect on the Academic Performance," International Journal of Distance Education Technologies (IJDET) 17.3 (2019): 25-36.

10. J. Yip, et al. "Improving quality of teaching and learning in classes by using augmented reality video," Computers \& Education 128 (2019): 88-101.

11. P. Pandey and C. Zimitat, "Medical students' learning of anatomy: memorisation, understanding and visualisation." Medical education 41.1 (2007): 7-14.

12. T. Blum, S. M. Heining, O. Kutter, and N. Navab, "Advanced training methods using an augmented reality ultrasound simulator," 2009 8th IEEE International Symposium on Mixed and Augmented Reality. IEEE, 2009.

13. R. Umeda, M. A. Seif, H. Higa, and Y. Kuniyoshi, "A medical training system using augmented reality," 2017 International Conference on Intelligent Informatics and Biomedical Sciences (ICIIBMS). IEEE, 2017.

14. S. S. Jamali, et al. "Utilising mobile-augmented reality for learning human anatomy," Procedia-Social and Behavioral Sciences 197 (2015): 659-668.

15. T. Blum, et al. "mirracle: An augmented reality magic mirror system for anatomy education," 2012 IEEE Virtual Reality Workshops (VRW). IEEE, 2012.

16. P. Stefan, et al. "An AR edutainment system supporting bone anatomy learning," 2014 IEEE Virtual Reality (VR). IEEE, 2014.

17. S. Hossain, et al. "Is English as a medium of instruction problem for undergraduate medical students?," Journal of Armed Forces Medical College, Bangladesh 6.2 (2010): 32-36.

\section{APPENDIX}

This section contains the questionnaire that was distributed among students to collect their feedback.

Feedback form:

Please put your valuable feedback here.

I am interested in AR based learning system because it gives better understanding through visualization.
(A) Strongly Agree
(B) Agree
(C) Neutral
(D) Disagree
(E) Strongly Disagree

This app will help me to enhance learning.

(A) Strongly Agree

\section{Published By:}



(B) Agree
(C) Neutral
(D)Disagree
(E) Strongly Disagree

This AR based app is easy to use.
(A) Strongly Agree
(B) Agree
(C) Neutral
(D) Disagree
(E) Strongly Disagree

I do not need any technical support to use this application.
(A) Strongly Agree
(B) Agree
(C) Neutral
(D) Disagree
(E) Strongly Disagree

It would be better if it contains more models as well as features.
(A) Strongly Agree
(B) Agree
(C) Neutral
(D) Disagree
(E) Strongly Disagree

In my opinion, this app is helpful for first year medical students only.
(A) Strongly Agree
(B) Agree
(C) Neutral
(D) Disagree
(E) Strongly Disagree

\section{AUTHORS PROFILE}

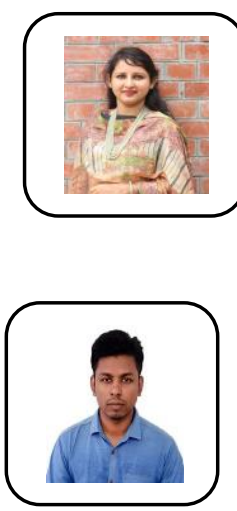

Rubaiya Hafiz received her B.Sc. and M. Sc. in Computer Science and Engineering from Jahangirnagar University, Savar, Dhaka, Bangladesh. She is currently working as a Senior Lecturer at Daffodil International University, Dhaka, Bangladesh. Her research interests include Artificial Intelligence, Machine Learning, Image Processing and HCI.

Jahidul Hasan has completed his graduation from Daffodil International University, Dhaka, Bangladesh in Computer Science and Engineering. $\mathrm{He}$ is interested in Augmented and Virtual Reality. Currently he is working as an AR/VR game developer in Dreamerz Lab Ltd, Lalmatia, Dhaka.

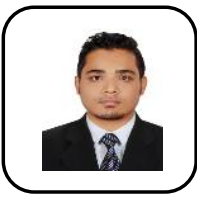

Md. Azizul Hakim has completed his graduation from Ahsanullah University of Science and Technology, Dhaka, Bangladesh and post- graduation from United International University, Dhaka, Bangladesh in Computer Science and Engineering. Currently he is working as a Lecturer at Daffodil International University, Dhaka, Bangladesh. His research interests include Data Mining, Machine Learning and HCI. 